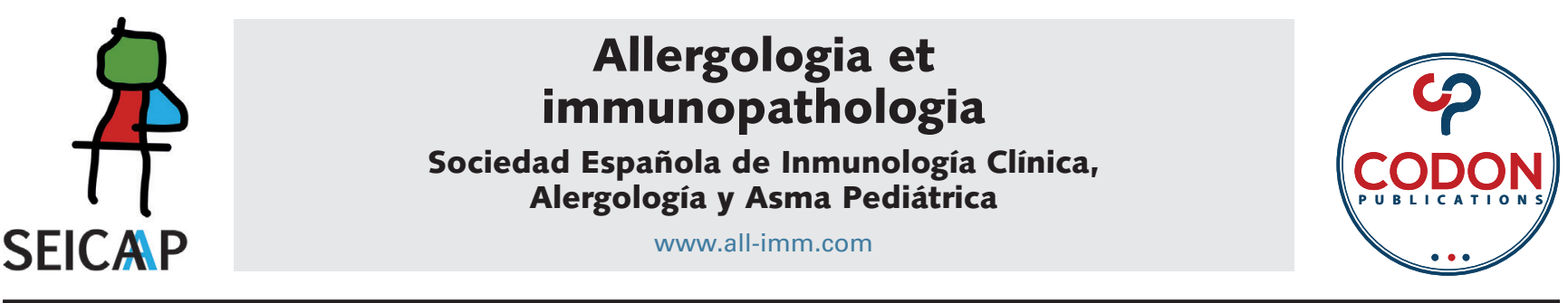

\title{
Managing food allergy immunotherapy in children during the COVID-19 pandemic
}

\author{
Simona Barni, MD*, Mattia Giovannini, MD, Lucrezia Sarti, MD, Giulia Liccioli, MD, \\ Benedetta Biagioni MD, Elio Novembre, MD, PhD, Francesca Mori, MD, PhD
}

Meyer Children's Hospital, Florence, Italy

Received 20 February 2020; Accepted 14 August 2020

Available online 2 January 2021

\author{
KEYWORDS \\ children; \\ COVID-19; \\ food allergy; \\ oral immunotherapy
}

\begin{abstract}
Food allergy immunotherapy is a promising allergen-specific approach to manage food allergy in children, although it is not exempt from adverse events, even severe. The adverse events are not predictable and furthermore cofactors can play a role in triggering them. During the COVID-19 pandemic, patients on food allergy immunotherapy should be provided with suggestions on how to proceed in the event of COVID-19 infection occurring or is suspected. These recommendations would be of support to clinical practitioners dealing with patients on food allergy immunotherapy since there is little data in the literature on the topic.

(c) 2021 Codon Publications. Published by Codon Publications.
\end{abstract}

\section{Introduction}

The Coronavirus Disease-19 (COVID-19) outbreak was declared a pandemic by the World Health Organization in March 2020. ${ }^{1}$ This unprecedented situation presents a unique challenge for patients with IgE-mediated food allergy, including those on oral food allergy (FA)immunotherapy (IT). ${ }^{2}$ The aim of this paper is to share our experience in managing FA-IT during the COVID-19 pandemic, supporting patients who are undergoing this treatment and their families. It has been shown that specific allergen IT does not cause any systemic immunodeficiency that would increase the risk of COVID-19 infection. ${ }^{3}$ As a matter of fact, IT induces an immunological mechanism in the target antigen/allergen-specific $T$ and $B$ cells that does not promote viral infections. ${ }^{3}$ FA-IT is a promising allergen-specific approach of FA management that consists in assuming progressively increasing amounts of the culprit food until a daily maintenance dose is reached. ${ }^{4}$ Afterwards, the patient should take it at home on a regular basis. ${ }^{4}$ The daily intake of the maintenance dose is mandatory to attain the state of desensitization in which the patient is able to consume the offending food safely. ${ }^{5}$ However, oral FA-IT is hampered by adverse events (AEs), ${ }^{6}$ the majority of which are mild and self-limiting, ${ }^{7}$ but systemic allergic reactions with the necessity to administer intramuscular epinephrine can occur as well. ${ }^{8}$ Moreover, the occurrence of AEs during the maintenance phase is possible, even with doses previously well tolerated for weeks or months. They are unpredictable, and cofactors, such as intercurrent viral

*Corresponding author: Simona Barni, MD. Viale Pieraccini, 24, 50139 Florence, Italy. Email address: simonabarni@hotmail.com 
infections, exercise, and teething in children ${ }^{9}$ can play a role as a trigger as well. Other cofactors which contribute to eliciting AEs during IT are poorly controlled asthma, seasonal pollen allergy, and consumption of the food dose on empty stomach. ${ }^{4}$ Furthermore, it must be considered that food-related anxiety, especially during the COVID-19 pandemic, may be increased by the fear of possible AEs. For that reason, it is paramount to minimize the possibility of provoking severe reactions which would require hospital setting care with the consequent risk of being infected by the Severe Acute Respiratory Syndrome-Coronavirus-2 (SARS-CoV-2). The recommendations for the management of an acute anaphylaxis episode at home during the COVID19 pandemic have been outlined by experts' opinion. ${ }^{2}$ Additionally, the patient must be provided with an emergency action plan, including epinephrine auto-injector. ${ }^{2}$ It has been established that the commonly prescribed anti-allergic drugs such as antihistamines and bronchodilators do not increase the risk of acquiring SARS-CoV-2 infection, ${ }^{10}$ and neither do oral steroids to treat an asthma attack..$^{11,12}$

At the same time, it would be essential not to interrupt an already ongoing oral FA-IT in order to avoid compromising the effect of the desensitization that has already been achieved. This aspect could be challenging to obtain, if the parents of patients under IT have been infected by SARSCoV-2. For this reason, they would not be able to take care of their children, or give the maintenance dose, and they would be obligated to delegate other caregivers who are not trained to cope with possible allergic reactions. Therefore, it is easier to stop the FA-IT than to continue it. Due to the significant emotional impact that families have to bear in this particular situation, our hospital has set up a psychological service, through telemedicine, for their daily support.

Additionally, the COVID-19 pandemic has also had some positive aspects as experienced by our allergic children's families. For instance, since the children are confined in quarantine, the risk of catching a viral infection is very low and, as a consequence, the threat of AEs triggered by infection is reduced; by not doing sports on a regular basis, the children are able to take the maintenance dose every day without the risk of exercise ${ }^{9}$ as a trigger factor. In addition, the possibility of contamination (direct and indirect $)^{13}$ during meal preparation is minimal as meals are prepared by the parents and consumed at home. The same risk is reduced also because the children do not participate in social events such as parties. Spending more time with their children, parents are trained to treat any eventual allergic reactions better than other relatives. Lastly, in case of reactions parents can easily reach the emergency department because of the lockdown.

Since there is little data in the literature on oral FA-IT, our recommendations, resulting from our clinical practice, may change based on new pieces of scientific evidence. For this reason, they should be continuously revised with knowledge of new information about COVID-19.

\section{Recommendations for non-infected patients during the COVID-19 pandemic}

Interrupting oral FA-IT is not advised. Oral FA-IT should be continued during the COVID-19 pandemic in patients with negative test results [real time-polymerase chain reaction (RT-PCR)].

If the patient does not present allergic symptoms with the maintenance dose at home, it is recommended to continue the consumption of the actual maintenance dose.

If the patient presents recurrent allergic symptoms (not anaphylaxis) with the maintenance dose at home, it is recommended to reduce the current maintenance dose by at least half.

If the patient presents an anaphylactic reaction with the maintenance dose at home, first of all, it is recommended to manage the anaphylaxis episode ${ }^{2}$ and interrupt the oral FA-IT until regular practice is resumed.

\section{Recommendations in diagnosed SARS-CoV-2 infected patients}

Interrupting oral FA-IT is advised. Oral FA-IT should be discontinued by symptomatic patients with positive test results (RT-PCR).

\section{Recommendations in suspected SARS-CoV-2 infected patients}

Interrupting oral FA-IT is not advised for an asymptomatic patient with exposure or contact to SARS-CoV-2 positive individuals. Oral FA-IT should be continued, ${ }^{14}$ reducing the current maintenance dose by half in the event of suspected symptoms (fever and at least one sign/symptom of respiratory disease such as cough or shortness of breath).

\section{Recommendations in recovered patients after a SARS-CoV-2 infection}

Resuming oral FA-IT is advised

- at home for those patients who suspended the maintenance dose for not more than 2 weeks;

- in the hospital for patients who suspended the maintenance dose for more than 2 weeks.

\section{Acknowledgments}

A special thank you goes to the association of Meyer Children's Hospital "Cibo Amico" that supports children with food allergy and their families every day.

\section{Funding}

This research did not receive any specific grant from funding agencies in the public, commercial, or not-for-profit sectors.

\section{Conflict of interest}

The authors declare that they have no conflict of interest. 


\section{References}

1. Cucinotta D, Vanelli M. WHO declares COVID-19 a pandemic. Acta Biomed. 2020;91(1):157-60. https://doi.org/10.23750/ abm.v91i1.9397

2. Casale TB, Wang J, Nowak-Wegrzyn A. Acute at home management of anaphylaxis during the Covid-19 pandemic. J Allergy Clin Immunol Pract. 2020;8(6):1795-7. https://doi. org/10.1016/j.jaip.2020.04.022

3. Klimek L, Jutel M, Akdis C, Bousquet J, Akdis M, Bachert C, et al. Handling of allergen immunotherapy in the COVID-19 pandemic: An ARIA-EAACI statement. Allergy. 2020;75(7):1546-54. https://doi.org/10.1111/all.14336

4. Gernez Y, Nowak-Węgrzyn A. Immunotherapy for food allergy: Are we there yet? J Allergy Clin Immunol Pract. 2017;5:250-72. https://doi.org/10.1016/j.jaip.2016.12.004

5. Pajno GB, Castagnoli R, Muraro A, Alvaro-Lozano M, Akdis CA, Akdis $M$, et al. Allergen immunotherapy for lgE-mediated food allergy: There is a measure in everything to a proper proportion of therapy. Pediatr Allergy Immunol. 2019;30:415-22. https://doi.org/10.1111/pai.13042

6. Pajno GB, Fernandez-Rivas M, Arasi S, Roberts G, Akdis CA, Alvaro-Lozano $M$, et al. EAACl guidelines on allergen immunotherapy: IgE-mediated food allergy. Allergy. 2018;73:799-815. https://doi.org/10.1111/all.13319

7. Nurmatov U, Devereux G, Worth A, Healy L, Sheikh A. Effectiveness and safety of orally administered immunotherapy for food allergies: A systematic review and metaanalysis. Br J Nutr. 2014;111:12-22. https://doi.org/10.1017/ S0007114513002353
8. Brozek JL, Terracciano L, Hsu J, Kreis J, Compalati E, Santesso N, et al. Oral immunotherapy for IgE-mediated cow's milk allergy: A systematic review and meta-analysis. Clin Exp Allergy 2012;42:363-74. https://doi.org/10.1111/j.13652222.2011.03948.x

9. Anagnostou K. Food immunotherapy for children with food allergies: State of the art and science. Curr Opin Pediatr. 2018;30:798-805. https://doi.org/10.1097/MOP.000000000000 0684

10. Brough HA, Kalayci O, Sediva A, et al. Managing childhood allergies and immunodeficiencies during respiratory virus epidemics - The 2020 COVID-19 pandemic. Pediatr Allergy Immunol. 2020;31(5):442-8. https://doi.org/10.1111/pai.13262

11. COVID-19: GINA answers to frequently asked questions on asthma management. Global Initiative for Asthma (GINA); 2020. https://ginasthma.org/covid-19-gina-answers-to - frequently- asked-questions-on-asthma-management/ (accessed 11 Apr 2020).

12. BTS advice for healthcare professionals treating patients with asthma. https://www.britthoracic.org.uk/document-library/ quality-improvement/covid-19/bts-advice- forhealthcare-professionals-treating-patients-with-asthma/ (accessed $5 \mathrm{Apr}$ 2020).

13. Taylor SL, Baumert JL. Worldwide food allergy labeling and detection of allergens in processed foods. Chem Immunol Allergy. 2015;101:227-34. https://doi.org/10.1159/000373910

14. Riggioni $C$, Comberiati $P$, Giovannini $M$, Agache I, Akdis $M$, Alves-Correia $M$, et al. A compendium answering 150 questions on COVID-19 and SARS-CoV-2. Allergy. 2020;75(10):250341. https://doi.org/10.1111/all.14449 